\title{
ANÁliSE COMPARATIVA dOS MODELOS DE AVALIAÇÃO DAS PRÁTICAS DE GOVERNANÇA NAS COOPERATIVAS
}

\author{
COMPARATIVE ANALYSIS OF TWO AVALIAÇÃO MODELS DAS GOVERNANÇA \\ NAS COOPERATIVE PRACTICES
}

\author{
Viviane Cristina da Cunha \\ Lesley Carina do Lago Attadia Lago ${ }^{\text {II }}$
}

\begin{abstract}
RESUMO
Este trabalho tem como objetivo analisar criticamente os modelos de avaliação das práticas de governança corporativa nas cooperativas, buscando identificar os fatores de convergência e os aspectos diferenciadores. Para tanto foi realizada uma pesquisa de natureza teórica, caráter descritivo e abordagem qualitativa, sendo utilizado como procedimento de coleta de dados a pesquisa bibliográfica e como procedimento de análise de dados a técnica de análise de conteúdo. Observou-se que cada modelo apresenta sua especificidade e sua contribuição para avaliar as práticas de governança dentro das cooperativas. Os resultados mostraram que a construção de um modelo de avaliação das práticas de governança corporativa para cooperativas é ainda um processo em evolução, sendo os principais constructos adotados como parâmetros de avaliação: os valores e princípios cooperativistas, a estrutura de poder, o sistema normativo interno e o sistema normativo externo.
\end{abstract}

Palavras-chaves: Governança Corporativa. Gestão Cooperativa. Modelos de Avaliação das Práticas de Governança.

\begin{abstract}
This paper aims to critically analyze the models for evaluating corporate governance practices in the cooperative, seeking to identify the convergence factors and the differentiating aspects. For chat, a research of theoretical nature, descriptive character and qualitative approach was carried out, being used as a data collection procedure the bibliographic research and as a data analysis procedure the content analysis technique. It was observed that each model presents its specificity and its contribution to evaluate governance practices within cooperatives. The necessary results that the construction of an evaluation model of corporate governance practices for cooperatives is still an evolving process, with the main constructs adopted as evaluation parameters: the cooperative values and principles, the power structure, the internal regulatory system and the external regulatory system.
\end{abstract}

Keywords: Corporate governance. Cooperative Management. Governance Practice Assessment Models.

Data de submissão do artigo: 30/06/2021.

Data de aprovação do artigo: 26/10/2021.

\footnotetext{
I Mestranda em Administração, FCAV- Unesp - Jaboticabal - Brasil. E-mail: viviane.cunha@unesp.br

II Profa. Dra. da FCAV- Unesp - Jaboticabal- Brasil. E-mail: lesley.attadia@unesp.br
} 


\section{(i⿵⿰丿⿺⿻⿻一㇂㇒丶𠃌⿴囗十)}

DOI: $10.33635 /$ sitefa.v4i1.190

\section{INTRODUÇÃO}

A governança corporativa pode ser conceituada como o conjunto de valores de valores, princípios e mecanismos de gestão que rege o sistema de poder de uma organização (CVM, 2002; AGUILERA, CUERVO-CAZURRA, 2009; WEITZNER, PERIDIS, 2011; ANDRADE, ROSSETTI, 2014; NOGUEIRA, 2018, PICCHI et al., 2021a). Do ponto de vista operacional, as práticas de governança protegem os interesses dos stakeholders, minimizam os conflitos de agência e a assimetria de informações (DUTRA e SAITO, 2002; BØHREN e ØDEGAARD, 2003; LUZ e PAGLIARUSSI, 2012; BACH et al., 2015; IBGC, 2016; NOGUEIRA, 2018; PICCHI et al., 2021b). Estrategicamente, a governança corporativa contribui para a institucionalização da organização, para consolidação da imagem da empresa e para o controle efetivo do desempenho empresarial (SILVEIRA, 2004; D'AVENI et al., 2010; WEITZNER; PERIDIS, 2011; BRINKHUES et al., 2015; CARVALHO et al., 2015; PRATA; FLACH, 2021).

A implantação de práticas de governança proporciona às organizações, sejam de capital aberto ou fechado, diversos benefícios como por exemplo: o fortalecimento da ética nas relações entre os diferentes stakeholders, o estreitamento do relacionamento entre os acionistas e administradores ao eliminar conflitos de interesses, a promoção da transparência na gestão e nos controles contabeis e financeiros; e o incremento nos esforços de melhoria contínua que contribuem para a conquista de novos patamares de desempenho e competitividade (MAESTRI et al., 2016; PICCHI, 2017; FERREIRA et al., 2019; OLIVEIRA; FONTES FILHO, 2021).

Partindo-se da premissa que as práticas de governança corporativa podem beneficiar diferentes tipos de organização (SILVEIRA, 2010; DUARTE JUNIOR, 2016; SOUZA; BAIDYA, 2016, OLIVEIRA; FONTES FILHO, 2021), surge a ideia de estudar como elas vêm sendo articuladas pelas cooperativas.

As cooperativas são arranjos organizacionais, cuja formação baseia-se nos princípios doutrinários do cooperativismo, sendo constituídas por uma associação autônoma de pessoas que se unem, voluntariamente, para satisfazer aspirações e necessidades econômicas, sociais e culturais comuns, por meio de uma empresa de propriedade coletiva e democraticamente gerida (CARDOSO, 2014; DUARTE, JESUS-LOPES; SANTOS, 2016; OCBSP, 2017).

Por apresentarem um estrutura organizacional distinta das organizações tradicionais e um modelo de gestão e tomada de decisão participativo, a adoção de práticas de governança corporativa podem mitigar conflitos de interesses entre os diferentes stakeholders, reduzir os custos de transação das operações e contribuir para a formação de um modelo de gestão e controle que possa, ao mesmo tempo, preservar os princípios cooperativistas e garantir a consecução dos objetivos estratégicos de caráter econômico, social e ambiental dessas organizações (ZYLBERSZTAJN, 1994; SHLEIFER; VISHNY, 1997; CORNFORTH, 2004; BIALOSKORSKI NETO; BARROSO; REZENDE, 2012; TOMAZ et al., 2018)

$\mathrm{Na}$ literatura, observa-se uma lacuna em relação ao estudo de modelos de avaliação das práticas de governança em cooperativas:

a) Em uma avaliação sobre o perfil das pesquisas sobre o tema "cooperativas", publicadas nos Encontros da Associação Nacional de Pós-Graduação e Pesquisa em Administração (EnANPAD) entre 2010 e 2014, foi possível constatar que os estudos relacionados ao tema são empíricos, caracterizando-se por estudos de caso e pesquisas de 


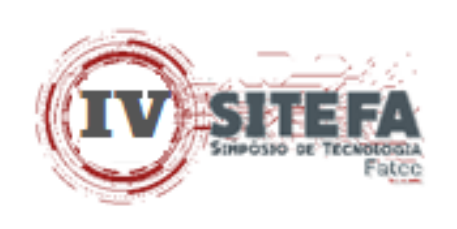

campo, abordando predominantemente aspectos relacionados as áreas de Economia Solidária e Empreendedorismo (DUARTE; JESUS-LOPES; SANTOS; 2016).

b) Em um estudo bibliométrico sobre o tema avaliação do desempenho organizacional em cooperativas de crédito, nas bases de dados Scielo, Scopus e Web of Science, foi observado que os conhecimentos sobre o assunto não estão consolidados (MARTINS et al., 2017);

c) Em uma pesquisa bibliométrica realizada na base Web of Science, abrangendo os anos de de 1960 e 2017, sobre a evolução das estudos relacionados a modelos de negócios cooperativos verificou-se que os Estados Unidos são o país com maior representatividade de trabalhos na área e que a pesquisa sobre o tema no Brasil ainda é incipiente (SILVA et al., 2018);

d) Em um trabalho bibliométrico, realizado na base Scopus, denominado "Governança cooperativa: mapeamento do perfil das publicações científicas internacionais (1991-2018)" foi possível concluir que a produção científica sobre o tema ainda é escassa e pulverizada entre vários autores e instituições de pesquisa, denotando baixo nível de cooperação entre os clusters de pesquisadores. Os autores destacam que a maioria dos trabalhos encontrados sobre a temática adotam uma vertente econômico-financeira ou tem um enfoque agropecuário (SANTOS; SANTOS; SILVA, 2020).

Corroborando com os estudos supracitados, um levantamento realizado na base de dados Scopus, para o desenvolvimento deste trabalho demonstrou claramente a existência de um gap na literatura sobre o tema Modelos de Governança em Cooperativas. O estudo englobou os anos de 2010 a 2020, utilizou como filtro as palavras-chaves "corporate governance", "cooperative organizations" e "model" , e estabeleceu como fatores limitadores da pesquisa artigos de livre acesso da área de "Business, Management e Accounting". A pesquisa retornou 68 trabalhos, dos quais foram validados apenas 4 artigos, considerados efetivamente aderentes ao tema, ou seja $5,88 \%$ da amostra.

Vale tambem destacar que as cooperativas apresentam grande relevância econômica e social em nível mundial por contribuirem enormemente para a dimuição da pobreza, para a geração de empregos diretos e indiretos, para o aumento da renda e para o desenvolvimento local (UNITED NATIONS, 2012; ACI, 2019); o que justifica a escolha do recorte setorial.

Assim, este trabalho tem como objetivo analisar criticamente os modelos de avaliação das práticas de governança em cooperativas encontrados na literatura, buscando identificar os pontos de convergência e os aspectos diferenciadores entre os modelos estudados.

\section{REVISÃO BIBLIOGRÁFICA}

Sendo uma sociedade de pessoas, com forma e natureza jurídica próprias, de natureza civil, não sujeitas a falência, as cooperativas são constituídas com o propósito de prestar serviços aos cooperados, distinguindo-se das demais sociedades pelas seguintes características (LEI 5764, 1971). A legislação brasileira que trata das sociedades cooperativas define-as tecnicamente como aquelas que observam e ressaltam, na sua configuração jurídica, nitidamente os seguintes traços (WAKULICZ; OLIVERIA FILHO, 2015):

a) é uma sociedade de pessoas, constituída em razão das pessoas que se unem para formar a cooperativa;

b) tem forma e natureza jurídica próprias, isto é, sua organização, funcionamento, constituição e modo de atuar estão preconizados na própria Lei das sociedades cooperativas, sob o amparo de regras do direito civil, excluídas as disciplinadoras das sociedades comerciais; 


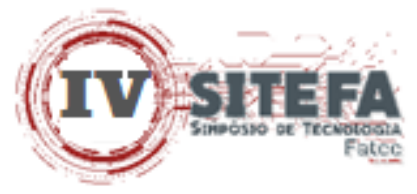

c) não tem fim lucrativo, já que visa tão somente à prestação de serviços aos associados; e

d) não é sujeita a falência, já que se aplica o mesmo procedimento previsto, em caso de solução, para a liquidação extrajudicial.

As cooperativas apresentam algumas características peculiares que as diferenciam das demais organizações e que explicam o seu funcionamento (SIQUEIRA; BIALOSKORSKI NETO, 2014; MILANE, 2017; CARPES; CUNHA et al., 2018):

a) a primeira refere-se ao fato de sua atividade fim está diretamente relacionada com as necessidades e serviços demandados pelos seus associados;

b) a segunda diz respeito ao fato de que os seus proprietários detêm e utilizam coletivamente o patrimônio e os serviços da cooperativa, fazendo com que as decisões de investimentos nessas organizações sejam tomadas procurando-se atender aos interesses dos cooperados/proprietários;

c) a terceira está relacionada à forma de controle da cooperativa, que é exercido por membros eleitos, em assembleia geral, para compor o conselho de administração;

d) a quarta trata-se dos retornos aos cooperados, os quais acontecem de forma proporcional ao volume de negociação que este manteve junto à cooperativa e não com base na cota de capital integralizada; e

e) a quinta está ligada à forma da distribuição da propriedade e controle: não há uma separação entre propriedade e controle nos empreendimentos cooperativos, ou seja, o associado é ao mesmo tempo usuário e proprietário de seu negócio, o que pode levar a cooperativa a uma situação de ineficiência, já que decisões estratégicas das cooperativas podem ser influenciadas por necessidades particulares dos associados;

f) a sexta relaciona-se ao seu aspecto local/regional: estas organizações estão restritas a uma determinada área de abrangência, ou seja, estão vinculadas às regiões as quais os seus sócios habitam, atuando como um elemento dinamizador da economia local, na medida em que investem nas necessidades dos seus sócios e distribuem as sobras de recursos financeiros localmente.

$\mathrm{Na}$ medida em que a cooperativa cresce essas especificidades tornam-se mais complexas, fazendo-se necessário a adoção de um conjunto de práticas gerenciais que possam proteger a propriedade e mitigar os conflitos de agência (ZYLBERSZTAJN, 1994; SILVA, SOUZA; SILVA, 2015; CARPES; CUNHA, 2018). Essas especificidades podem não só criar lacunas estratégicas e operacionais, que à longo prazo, acabam comprometendo o desempenho da cooperativa, como também podem impactar a estrutura de governança dessas organizações, colocando em risco a sua sustentabilidade (COLIN, 2007; SIQUEIRA; BIALOSKORSKI NETO, 2014; PENG et al., 2019). cooperativas.

O Quadro 1 sintetiza os principais problemas de governança observados nas

Quadro 1 - Problemas de governança nas cooperativas

\begin{tabular}{|c|c|c|}
\hline Problema & Descrição & Autores \\
\hline $\begin{array}{l}\text { Arquitetura } \\
\text { contratual que } \\
\text { apresenta } \\
\text { direitos de } \\
\text { propriedade }\end{array}$ & $\begin{array}{l}\text { No papel de proprietários, os cooperados têm direito a } \\
\text { receber os ganhos ou lucros residuais advindos das } \\
\text { atividades realizadas pela cooperativa. No entanto, } \\
\text { por seguir uma lógica econômica socialista e ter como } \\
\text { fundamento a ausência de fins lucrativos, o que }\end{array}$ & $\begin{array}{l}\text { COOK (1995); } \\
\text { BIALOSKORSKI } \\
\text { NETO (2004); } \\
\text { PIVOTO (2013). }\end{array}$ \\
\hline
\end{tabular}




\begin{tabular}{|c|c|c|}
\hline $\begin{array}{l}\text { vagamente } \\
\text { definidos }\end{array}$ & $\begin{array}{l}\text { acontece na prática é não há clareza sobre a destinação } \\
\text { das sobras de recursos financeiros. }\end{array}$ & \\
\hline $\begin{array}{l}\text { Problema do } \\
\text { carona ou } \\
\text { freerider }\end{array}$ & $\begin{array}{l}\text { Este ocorre quando os benefícios da cooperativa } \\
\text { acabam por beneficiar também membros não } \\
\text { cooperativados, ou seja, que não têm atividades e } \\
\text { custos para com a organização, mas que se beneficiam } \\
\text { dos resultados econômicos pela cooperativa. Se este } \\
\text { benefício é percebido por outros agentes, acaba por } \\
\text { desestimular a participação de novos membros na } \\
\text { cooperativa, já os benefícios são públicos e comuns. }\end{array}$ & MILANI (2017) \\
\hline $\begin{array}{l}\text { Problema do } \\
\text { Horizonte }\end{array}$ & $\begin{array}{l}\text { Este problema ocorre quando um grupo de membros } \\
\text { reivindica o lucro residual sobre o lucro líquido, } \\
\text { entretanto este lucro é gerado por um ativo menor do } \\
\text { que a vida produtiva deste ativo. O problema do } \\
\text { horizonte cria um desincentivo para os membros } \\
\text { investirem no crescimento da cooperativa, } \\
\text { desestimulando os cooperados a imobilizarem capital } \\
\text { por um longo período. Essa situação acaba por criar } \\
\text { uma cultura execução de projetos de curto prazo em } \\
\text { detrimento de projetos de investimentos de longa } \\
\text { duração, voltados à inovação, diferenciação de } \\
\text { produtos e desenvolvimento de marcas. }\end{array}$ & $\begin{array}{l}\text { ZYLBERSZTAJN } \\
(2002) \\
\text { BIALOSKORSKI } \\
\text { NETO (2004) } \\
\text { MILANI }(2017)\end{array}$ \\
\hline $\begin{array}{l}\text { Problema do } \\
\text { Portfólio }\end{array}$ & $\begin{array}{l}\text { Este problema ocorre devido à impossibilidade dos } \\
\text { cooperados ajustarem o seu portfólio de ativos na } \\
\text { cooperativa para corresponder com suas preferências } \\
\text { de risco pessoal por causa da não transferência e } \\
\text { liquidez, bem como pela falta de instrumentos } \\
\text { financeiros de apreciação das quotas-partes nas } \\
\text { cooperativas. Isso significa que é mais difícil alinhar } \\
\text { as estratégias de investimento e negócios da } \\
\text { cooperativa com as respectivas estratégias dos } \\
\text { cooperados. Desta forma, o melhor portfólio da } \\
\text { cooperativa pode não ser o melhor portfólio para todos } \\
\text { os cooperados, fazendo com que alguns alcancem seu } \\
\text { ótimo econômico e outros não, gerando, assim, } \\
\text { conflitos de interesses entre as partes. }\end{array}$ & PIVOTO (2013) \\
\hline $\begin{array}{l}\text { Problema de } \\
\text { controle ou } \\
\text { agência }\end{array}$ & $\begin{array}{l}\text { Está relacionado aos custos originados pelas } \\
\text { divergências que se estabelecem entre proprietários e } \\
\text { gestores da cooperativa }\end{array}$ & PIVOTO (2013) \\
\hline $\begin{array}{l}\text { Problemas do } \\
\text { custo de } \\
\text { Influência }\end{array}$ & $\begin{array}{l}\text { Surgem quando os cooperados tentam, de maneira } \\
\text { informal, influenciar as decisões da cooperativa em } \\
\text { benefício próprio. A magnitude dos custos de } \\
\text { influência depende de: (a) existência de uma } \\
\text { autoridade central, (b) os tipos de produtores que } \\
\text { governam a tomada de decisões, e (c) o grau de }\end{array}$ & $\begin{array}{l}\text { PIVOTO (2013) } \\
\text { MILANI (2017) }\end{array}$ \\
\hline
\end{tabular}




\begin{tabular}{|l|l|l|}
\hline & $\begin{array}{l}\text { homogeneidade ou conflito no interesse dos membros } \\
\text { cooperativa }\end{array}$ & \\
\hline
\end{tabular}

Fonte: Elaboração Própria (2021)

Nesse sentido a adoção de práticas de governança corporativa nas cooperativas, não só assegura o alcance dos objetivos e a aplicação dos principios cooperativistas, como também corrobora com a clara definição dos direitos de propriedade, com o estabelecimento de diretrizes sobre a composição e funcionamento do conselho de administração e do conselho fiscal, e com a implantação de boas práticas de gestão e de auditoria da organização, de forma a se alcançar um equilíbrio na relação entre os gestores, órgãos de controle e cooperados, alinhando os interesses das partes (COOK, 1995; SERIGATI, 2008; IBGC, 2015; OCB, 2017; FARINELLA; VESCO; FAVRETTO, 2019; MILANI et al., 2020).

\section{PROCEDIMENTOS METODOLÓGICOS}

Este trabalho tem caráter teórico (SALOMON, 1991), sendo caracterizado como uma pesquisa descritiva (FACHIN, 2001) e de abordagem qualitativa (BRYMAN, 1989). O método de coleta de dados adotado foi a pesquisa bibliográfica (GIL, 2002), sendo realizada nas bases SCOPUS, SPELL e GOOGLE SCHOLAR. Para a análise dos trabalhos selecionados foi utilizada a técnica de análise de conteúdo (GODOI; BANDEIRA-DE-MELLO; SILVA, 2006).

\section{ANÁLISE E DISCUSSÕES}

Conforme explicitado na introdução, este trabalho tem como objetivo analisar criticamente os modelos de avaliação das práticas de governança em cooperativas encontrados na literatura, buscando identificar os pontos de convergência e os aspectos diferenciadores entre os modelos eles. O Quadro 2 apresenta os trabalhos encontrados na literatura que tratam da temática proposta:

Quadro 2 - Modeloa de Avaliação das Práticas de Governança Corporativa Analisados

\begin{tabular}{|c|c|c|c|}
\hline ANO & AUTORES & TÍTULO & DESCRIÇÃO \\
\hline 2008 & $\begin{array}{c}\text { VILELA, R. H. } \\
\text { P }\end{array}$ & $\begin{array}{c}\text { Governança } \\
\text { corporativa em } \\
\text { cooperativas de } \\
\text { saúde: proposição } \\
\text { de um modelo } \\
\text { diagnóstico }\end{array}$ & $\begin{array}{l}\text { O modelo está estruturado em } 4 \text { dimensões: } \\
\text { sistemas de valores, estrutura de poder, } \\
\text { processos e sistemas de gestão, sistemas } \\
\text { normativos. Para cada dimensão do modelo } \\
\text { diagnóstico proposto, apresentam-se suas } \\
\text { perspectivas interna e externa e os } \\
\text { respectivos itens de verificações nas quais as } \\
\text { práticas de governança são avaliadas. } \\
\text { Complementando o modelo, a estrutura e a } \\
\text { hierarquia, são representadas pelo sistema de } \\
\text { pesos, sendo: P1 corresponde ao peso } \\
\text { ponderado da dimensão; P2 corresponde ao } \\
\text { peso ponderado da perspectiva; P3 } \\
\text { corresponde ao peso ponderado do Item de } \\
\text { verificação e P4 corresponde ao peso } \\
\text { ponderado das gradações. Durante o }\end{array}$ \\
\hline
\end{tabular}




\begin{tabular}{|c|c|c|c|}
\hline & & & $\begin{array}{l}\text { processo de diagnóstico é possível obter até } \\
1000 \text { pontos. O valor máximo de pontos que } \\
\text { uma cooperativa pode obter é total de pontos } \\
\text { a ser obtido é obtido pela fórmula } \\
\text { matemática, possuindo o modelo como valor } \\
\text { máximo da escala o total de } 1000 \text { pontos. } \\
\text { Dependendo do número de pontos } \\
\text { alcançados é possível enquadrar a } \\
\text { cooperativa analisada em } 4 \text { níveis de } \\
\text { governança: baixo, moderado, em } \\
\text { desenvolvimento ou avançado. }\end{array}$ \\
\hline 2014 & $\begin{array}{l}\text { SILVA, R. F; } \\
\text { SOUZA, A } \\
\text { SILVA, W. }\end{array}$ & $\begin{array}{c}\text { Governança } \\
\text { corporativa em } \\
\text { cooperativas } \\
\text { agropecuárias: } \\
\text { um modelo de } \\
\text { classificação com } \\
\text { aplicação da } \\
\text { ferramenta } \\
\text { WALK }\end{array}$ & $\begin{array}{l}\text { O modelo está estruturado de acordo com os } \\
\text { princípios da governança corporativa } \\
\text { (transparência; equidade; prestação de } \\
\text { contas e responsabilidade corporativa), } \\
\text { sendo construído com base na ferramenta de } \\
\text { análise multicritério ligada ao método } \\
\text { Preference Ranking Organization Method } \\
\text { for Enrichment Evaluations (Promethee), } \\
\text { sendo operacionalizado pelo software } \\
\text { WALK[ER]. A partir dos resultados obtidos } \\
\text { é possível obter uma comparação entre as } \\
\text { cooperativas analisadas e estabelecer um } \\
\text { ranking entre elas. }\end{array}$ \\
\hline 2018 & $\begin{array}{c}\text { CARPES, A. M. } \\
\text { S. } \\
\text { CUNHA, P. R. }\end{array}$ & $\begin{array}{l}\text { Mecanismos de } \\
\text { Governança } \\
\text { Corporativa nos } \\
\text { Diferentes Ciclos } \\
\text { de Vida de } \\
\text { Cooperativas } \\
\text { Agropecuárias do } \\
\text { Sul do Brasil }\end{array}$ & $\begin{array}{l}\text { O modelo proposto objetiva analisar a } \\
\text { relação entre os mecanismos de governança } \\
\text { corporativa (MCG) e os estágios de ciclo de } \\
\text { vida organizacional das cooperativas (CVO), } \\
\text { buscando comprovar a existência de uma } \\
\text { correlação positiva entre os constructos. Para } \\
\text { a realização do estudo foram aplicadas as } \\
\text { seguintes técnicas: análise estatística, } \\
\text { descritiva, Technique for Order Preference } \\
\text { by Similarity to Ideal Solution (TOPSIS) e a } \\
\text { regressão logística multinomial. }\end{array}$ \\
\hline 2019 & $\begin{array}{c}\text { CANQUERINO, } \\
\text { Y.K. }\end{array}$ & $\begin{array}{l}\text { O nível de adoção } \\
\text { das práticas de } \\
\text { governança } \\
\text { corporativa em } \\
\text { cooperativas no } \\
\text { oeste do paraná }\end{array}$ & $\begin{array}{l}\text { O modelo tem como propósito avaliar o nível } \\
\text { de adoção das práticas de governança } \\
\text { corporativa em cooperativas no Oeste no } \\
\text { Paraná, sendo estruturado nas seguintes } \\
\text { dimensões: estratégia, estrutura, processos } \\
\text { de gestão, sustentabilidade e perenidade. }\end{array}$ \\
\hline
\end{tabular}

Fonte: Elaboração Própria (2021)

O modelo proposto por Vilela (2008) tem como principal contribuição possibilitar a análise crítica de uma cooperativa em relação governança, permitindo não só classifica-la em um determinado nível (baixo, moderado, em desenvolvimento ou avançado), como também 


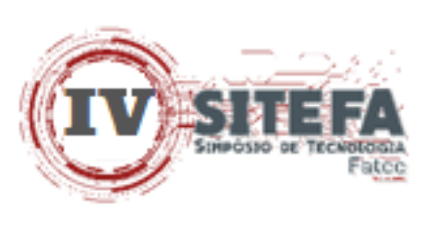

identificar qual é a dimensão que requer maior atenção por parte dos gestores (sistemas de valores, estrutura de poder, processos e sistemas de gestão, sistemas normativos).

Esse modus operandi é bastante benéfico para promover uma cultura de melhoria contínua em relação ao nível de governança e para incentivar o aprendizado dos funcionários sobre as diferentes práticas que permeiam cada uma das dimensões do modelo. Outra vantagem observada é que os itens de verificação contemplam os públicos interessados de âmbito interno e externo à cooperativa, permitindo uma avaliação mais hoslítica e clara dos pontos fortes e dos aspectos que precisam ser desenvolvidos para maximização de seus interesses. Finalmante, cabe destacar que o modelo é dotado de certa flexibilidade no que diz respeito à atribuição de pesos e pontos, de forma que cada cooperativa pode ajusta-lo a sua realidade (VILELA, 2008).

O modelo proposto por Silva, Souza e Silva (2014) apresenta 57 variáveis para avaliação de uma cooperativa quanto aos princípios de governança governança, sendo 16 pertencentes ao no critério transparência, 15 correspondentes ao critério equidade, 10 enquadradas no critério prestação de contas e 16 incluídas no critério responsabilidade corporativa. Tais variáveis influenciam no nível de Governança Corporativa de cada cooperativa e, consequentemente, na classificação gerada na análise. Com base nos diferentes graus de governança obtidos pela aplicação do modelo em diversas cooperativas, é possível agrupá-las em clusters; os quais podem ser identificados como: grupo de alto nível de governança, grupo de nível intermediário e grupo de baixo nível de governança. A utilização da análise multicritério, com o método Promethee e o foi WALK[ER] foi crítica para a viabilização e o sucesso de modelo.

Ao analisar a relação entre os mecanismos de governança corporativa (MCG) e os estágios de ciclo de vida organizacional das cooperativas (CVO), o modelo proposto por Carpes e Cunha (2018) buscou validar as seguintes hipóteses: (H1A) as cooperativas agropecuárias nos estágios iniciais possuem mecanismos de GC de participação dos cooperados mais desenvolvidos se comparadas às cooperativas em estágio de maturidade; (H1B) as cooperativas agropecuárias no estágio de declínio possuem mecanismos de GC de participação dos cooperados mais desenvolvidos se comparadas às cooperativas em estágio de maturidade; $(\mathrm{H} 2)$ as cooperativas agropecuárias nos estágios iniciais possuem mecanismos de GC conselho de administração mais desenvolvidos se comparadas às cooperativas classificadas em estágio de maturidade; (H3) as cooperativas agropecuárias no estágio de maturidade possuem mecanismos de governança corporativa auditoria mais desenvolvidos se comparadas às cooperativas classificadas em outros estágios de ciclo de vida organizacional.

Embora o modelo proposto por Carpes e Cunha (2018) não seja um instrumento de autoavaliação que possa ser utilizado pelas cooperativas no processo de monitoramento e aprendizado acerca do uso das práticas de governança pelas cooperativas, os achados da pesquisa desenvolvida tem grande valor ao comprovar que os mecanismos de GC de participação dos cooperados e conselho de administração são mais desenvolvidos nas fases iniciais do ciclo de vida das cooperativas e mais enfraquecidos a partir do estágio de maturidade, indicando claramente que a uma estrutura de maior complexidade e um modelo de gestão maduro resultam em uma menor presença da participação dos cooperados.

Outra contribuição que vale destacar é a constatação de que os mecanismos de GC relativos ao conselho de administração demonstram maior presença nos estágios iniciais do ciclo de vida das cooperativas, comparados aos demais; enquanto que os mecanismo de GC de auditoria são mais frequentes em cooperativas que se enquadram no estágio de maturidade.

No que diz respeito ao modelo proposto por Canquerino (2019), observa-se que ele abrange os principais elementos da governança corporativa, incluindo os princípios, os aspectos estruturais e práticas abordados na litertura, tendo como diferencial a incorporação das variáveis

Simpósio de Tecnologia (Sitefa) - Fatec Sertãozinho - SP, v. 4, n. 1, p. 376-389, 2021. ISSN 2675-7540 


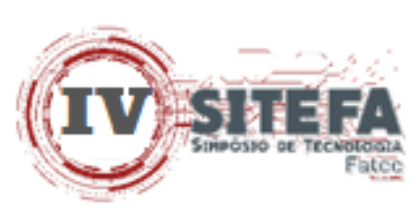

sustentabilidade e perenidade. Os resultados da pesquisa demonstraram que as dimensões "Sustentabilidade" e "Perenidade" são as que requerem maior nível de desenvolvimento por parte das cooperativas analisadas.

\section{CONIDERAÇÕES FINAIS}

Este trabalho teve como objetivo analisar criticamente os modelos de avaliação das práticas de governança em cooperativas encontrados na literatura, buscando identificar os pontos de convergência e os aspectos diferenciadores entre os modelos estudados.

Dos quatro modelos analisados observa-se que $75 \%$ deles utiliza a variável valores e princípios cooperativistas como constructo norteador do processo avaliativo. Nota-se que 50\% dos modelos propostos apresentam as variáveis estrutura de poder (agentes de governança), sistema normativo interno (instrumentos e práticas voltados especificamente à governança corporativa) e sistema normativo externo (práticas relacionadas ao cumprimento de leis e aspectos reguladores) em sua estrutura de análise avalitiva. Finalmente, as variáveis estágio do ciclo de vida, perenidade (ligada á sucessão) e sistemas e processos de gestão organizacional em $25 \%$ dos modelos analisados.

Pode-se dizer que a criação de modelo de avaliação das práticas de governança que permita a autoavaliação das cooperativas e a realização de estudos comparativos entre as organizações do setor ainda é um processo em construção. Chegar a um conjunto de variáveis que possa ser medido pode contribuir não só para o avanço da implementação das práticas de governança nas cooperativas de todas as naturezas, como também para uma melhor compreensão sobre como lidar com as práticas de governança nas diferentes fases do ciclo de vida das cooperativas.

\section{REFERÊNCIAS}

ALIANÇA COOPERATIVA INTERNACIONAL (ACI). What is a Co-operative? Disponível em: https://www.ica.coop/en/cooperatives/what-is-a-cooperative. 2016. Acesso em: 22 mar. 2019.

AGUILERA, R. V.; CUERVO-CAZURRA, A. Codes of good governance. Corporate Governance: An International Review, v. 17, n. 3, p. 376-387, 2009.

ANDRADE, A.; ROSSETTI, J. P. Governança corporativa: fundamentos, desenvolvimento e tendências. 7. ed. São Paulo: Atlas, 2014.

BACH, T. M.; KUDLAWICZ, C.; SOKULSKI, C. C.; SILVA, E. D. Eficiência e governança corporativa: um estudo em empresas de capital aberto. VII encontro de estudo em estratégia (3 Es), Brasília - DF: 21 a 23 de junho de 2015. Disponível em:

http://www.academia.edu/18450545/Efici\%C3\%AAncia_e_Governan\%C3\%A7a_Corporativ a_um_Estudo_em_Empresas_de_Capital_Aberto. Acesso em: 15 abr. 2017.

BIALOSKORSKI NETO, S. Gobierno y papel de los cuadros directivos en las cooperativas brasileñas: estudio comparativo. Revista de Economía Pública Social y Cooperativa, Valencia, n. 48, abr. 2004. 


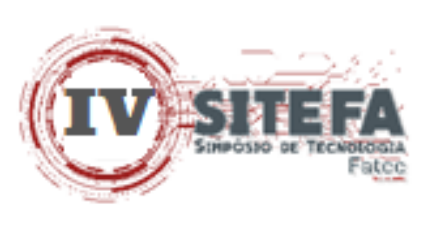

BIALOSKORSKI NETO, S.; BARROSO, M. F. G.; REZENDE, A. J. Co-operative governance and management control systems: an agency costs theoretical approach. Brazilian Business Review, 9 (2), 68-87 (2012)

BØHREN, Øyvind; ØDEGAARD, Bernt A. Governance and Performance Revisited. Brussels: SSRN, 2004. (ECGI Finance Working Paper, n. 28, 2003).

BRINKHUES, R. A.; MAÇADA, A. C. G.; FREITAS JÚNIOR, J. C. S.; LAJARA, T. T. Princípios e fatores motivadores na adoção de governança corporativa, da TI e da informação. XXXIX Encontro da ANPAD, Belo Horizonte - MG: 13 a 16 de setembro de 2015. Disponível em: https://www.researchgate.net/publication/281348167_Principios_e_Fatores_Motivadores_na_ Adocao_de_Governanca_Corporativa_da_TI_e_da_Informacao. Acesso em: 12 abr. 2017.

BRYMAN, A. Research methods and organization studies. London: Unwin Hyman, 1989.

CANQUERINO, Y. K. O nível de adoção das práticas de governança corporativa em cooperativas no oeste do paraná. Dissertação (mestrado), Universidade Estadual do Oeste do Paraná, Campus Marechal Cândido Rondon, Centro de Ciências Agrárias, Programa de Pós-Graduação em Desenvolvimento Rural Sustentável, 2019, 184 p.

CARDOSO, U. C. Cooperativa. Brasília: Sebrae, 2014. Disponível em: tecas.sebrae.com.br/chronus/ARQUIVOS_CHRONUS/bds/bds.nsf/65f0176ca446f4668643bc 4e4c5d6add/\$File/5193.pdf. Acesso: 27 fev. 2021

CARVALHO, C. C.; FORTE, S. H. A. C.; OLIVEIRA, O. V.; SALES, R. K. L. Mensuração da Capacidade de Governança Corporativa das Empresas Familiares do Mercado Tradicional para a migração ao Novo Mercado da BM\&FBovespa. VII encontro de estudo em estratégia (3 Es), Brasília - DF: 21 a 23 de junho de 2015.

CARPES, A. M. S.; CUNHA, P. R. Mecanismos de Governança Corporativa nos Diferentes Ciclos de Vida de Cooperativas Agropecuárias do Sul do Brasil. Revista Contabilidade, Gestão e Governança · v. $21 \cdot$ n. 1 · p.80-99 · jan. /abr. 2018

COLIN, Sven-Olof. Governance Strategy: a property right approach turning governance into action. Journal of Manage Governance, v. 11, n. 3, p. 215-237, 2007.

COMISSÃO DE VALORES MOBILIÁRIOS - CVM. Recomendações da CVM sobre Governança Corporativa. Junho de 2002. Disponível em:

http://www.cvm.gov.br/port/public/publ/ cartilha/cartilha.doc. Acesso em: 21 fev. 2019.

COOK, M. L. The future of US agricultural cooperatives: a neo-institucional approach. American Journal of Agricultural Economics, Oxford, v. 77, p. 1153-1159, dec. 1995.

CORNFORTH, C. The Governance of cooperatives and mutual associations: A paradox perspective. Annals of Public and Cooperative Economics, 75 (1), pp. 11-32. (2004) 
CARPES, A. M. S.; CUNHA, P.R. Mecanismos de Governança Corporativa nos Diferentes Ciclos de Vida de Cooperativas Agropecuárias do Sul do Brasil. Revista Contabilidade, Gestão e Governança. v. 21, n. 1, p. 80-99, jan. /abr. 2018.

D'AVENI, R. A. et al.. The Age of Temporary Advantage. Strategic Management Journal, Chicago, v. 31, n. 13, p. 1.371-1.385, 2010.

DUARTE, C. A. S.; JESUS-LOPES, J. C.; SANTOS, L. M. R. Cooperativas: um levantamento bibliométrico da produção científica do EnANPAD entre 2010-2014. Desafio Online, 4 (1) abril, 2016.

DUTRA, M. G. L.; SAITO, R. Conselhos de administração: análise de sua composição em um conjunto de companhias abertas brasileiras. Revista de Administração Contemporânea, v. 6, n. 2, p. 09-27, 2002.

FACHIN, O. Fundamentos de metodologia. São Paulo: Saraiva. 2001.

FARINELLA, F.; VESCO, A.D.; FAVRETTO, J. Princípios, valores, deveres e direitos cooperativistas: a visão dos associados de uma cooperativa agropecuária. RGC, Santa Maria, v. 6, n. 11, p. 127-154, Jan./Jun. 2019

FERREIRA, R. M.; LIMA, S.L.L.; GOMES, A.R.V; MELLO, G. R. Governança

Corporativa: um estudo bibliométrico da produção científica entre 2010 a 2016.

Organizações em contexto, São Bernardo do Campo, ISSNe 1982-8756. v. 15, n. 29, jan.-jun. 2019

GIL, A. C. Como elaborar projetos de pesquisa. 4. ed. São Paulo: Atlas, 2002.

GODOI, C. K; BANDEIRA-DE-MELLO, R.; SILVA, A.B. (org.). Pesquisa Qualitativa em Estudos Organizacionais: paradigmas, estratégias e métodos. São Paulo: Saraiva, 2006. $460 \mathrm{p}$.

IBGC. Instituto Brasileiro de Governança Corporativa. Código das Melhores Práticas de Governança Corporativa. 5. ed. São Paulo: IBGC, 2015. Disponível em: http://www.ibgc.org.br/userfiles/2014/files/CMPGPT.pdf. Acesso em: 06 maio. 2021.

LEI 5674 de 1971. Define a Política Nacional de Cooperativismo, institui o regime jurídico das sociedades cooperativas, e dá outras providências. Disponível em:

http://www.planalto.gov.br/ccivil_03/leis/15764.htm. Acesso em: 12 set. 2021.

LUZ, A. T. M.; PAGLIARUSSI, M. S. Práticas de governança corporativa e sua associação a uma variável de caráter contábil: um estudo. XXXVI Encontro da ANPAD, Rio de Janeiro RJ: 22 a 26 de setembro de 2012. Disponível em:

http://www.fucape.br/_public/producao_cientifica/2/ANTONIO\%20THADEU.pdf. Acesso em: 10 mai 2017. 


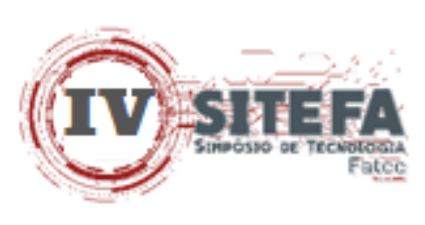

MAESTRI, C. O. N. M.; TAVARES, V. B.; PENEDO, S. T.; COELHO, R. R. A. Nível de governança corporativa prediz o desempenho da empresa? Evidências do mercado brasileiro. XL Encontro da ANPAD, Costa do Sauipe - BA: 25 a 28 de setembro de 2016.

MARTINS, P.; LIMA, E. P.; SCHENATTO, F. J. A.; BORTOLUZZI, S. C. Análise das características das publicações sobre avaliação de desempenho organizacional em cooperativas de crédito. Anais do Congresso Brasileiro de Engenharia de Produção, Ponta Grossa, PR, Brasil, 7. dezembro (2017).

MILANI, R. Análise dos problemas de governança em cooperativas de produtores de leite familiares. Dissertação (Mestrado) - Universidade Federal do Rio Grande do Sul, Centro de Estudos e Pesquisas em Agronegócios, Programa de Pós-Graduação em Agronegócios, Porto Alegre, RS, 2017.

MILANI, R.; BOSCARDIN, M.; SOUZA, M.; LAGO, A.; SPANAVELLO, M. Problemas de governança em cooperativas de produtores de leite no Estado do RS. RGC, Santa Maria, v. 7, Edição Especial, 2020

NOGUEIRA, F.E.A. Publicações em Governança Corporativa no Brasil. RMGC - Revista Metropolitana de Governança Corporativa, São Paulo, Vol.3 N.1, P. 54-78, Jan/jun. 2018. OCBSP (ORGANIZAÇÃO DAS COOPERATIVAS BRASILEIRAS). Contribuição cooperativista. 2017. Disponível em: http://ocesp.org.br. Acesso em: 20. abr. 2019.

OLIVEIRA, F.B.; FONTES FILHO, J.R. Mudanças nas configurações de governança corporativa e relações de agência: uma análise longitudinal em empresa de capital fechado. Cad. EBAPE.BR, v. 19, nº 3, Rio de Janeiro, jul./set. 2021

PENG, X.; LIANG, Q.; DENG, W.; HENDRIKSE, G. CEOs versus members' evaluation of cooperative performance: Evidence from China. The Social Science Journal. 56 (2). 55- 63. (2019).

PIVOTO, D. Os problemas dos direitos de propriedades difusos em cooperativas agropecuárias. 2013. Dissertação (Mestrado em Agronegócios) - Programa de Pós-graduação em Agronegócios, Centro de Estudos e Pesquisas em Agronegócios, Universidade Federal do Rio Grande do Sul, Porto Alegre, 2013.

PICCHI, M. R. Contribuições das práticas de governança corporativa no processo de profissionalização das empresas familiares do agronegócio: um estudo multicasos no segmento de implementos agrícolas. Dissertação (Mestrado). Programa de Mestrado Profissional em Administração. Jaboticabal, FCAV-UNESP, 2017.

PICCHI, M. R. CALIOGIONI, R.R.; PRATES, G.A.; MARQUES, E.F.; GALLI, L.C.L.A. Governança Corporativa no Contexto da Empresa Familiar: um Estudo de Caso no Segmento de Implementos Agrícolas. XIII Congresso de Administração, Sociedade e Inovação CASI. Rio de Janeiro: 20 a 21 de maio de 2021a 


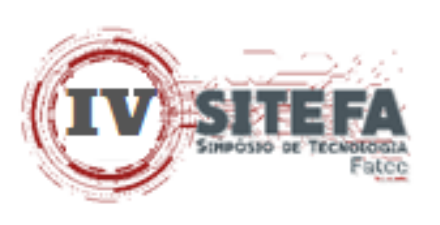

Práticas de governança corporativa e o processo de profissionalização da empresa familiar. VI SIMPÓSIO EM GESTÃO DO AGRONEGÓCIO - SGAgro. Jaboticabal: 9 a 11 de junho de $2021 \mathrm{~b}$

PRATA, B.C.; FLACH, L. Gerenciamento de resultados e governança corporativa: uma análise a partir da adoção das IFRS no Brasil. Revista Ambiente Contábil - UFRN - NatalRN. v. 13, n. 2, p. 41 - 62, jul./dez., 2021, ISSN 2176-9036.

SALOMON, D. V. Como fazer uma monografia. 2.ed. São Paulo: Martins Fontes, 1991. SERIGATI, F.C. Fidelidade e Governança Corporativa em Cooperativas: um estudo empírico com as cooperativas paulistas. 2008. Dissertação (Mestrado em Economia) - Fundação Getúlio Vargas, São Paulo, 2008.

SHLEIFER, A.; VISHNY, R. W. A survey of corporate governance. The Journal of Finance, 52(2), 737-783. (1997)

SILVA, J., OLIVEIRA, C., GARCIA, A., SUGANO, J., LUCCHESI, K. Um estudo bibliométrico de 1960 a 2017. Revista Vianna Sapiens, 9(1), 115-136. (2018).

SILVA, R. F; SOUZA, A; SILVA, W. Governança corporativa em cooperativas agropecuárias: um modelo de classificação com aplicação da ferramenta Walk. RACE, Revista de Administração, Contabilidade e Economia, Joaçaba: Ed. Unoesc, v. 14, n. 1, p. 313-332, jan./abr. 2015.

SILVEIRA, A. D. M. Governança corporativa e estrutura de propriedade: determinantes e relação com o desempenho das empresas no Brasil. 2004. $250 \mathrm{f}$. Tese (Doutorado em Administração) - Faculdade de Economia, Administração e Contabilidade da Universidade de São Paulo, São Paulo, 2004. Disponível em:

http://www.teses.usp.br/teses/disponiveis/12/12139/tde-23012005-200501/pt-br.php. Acesso em: 23 set. 2016.

SIQUEIRA, L. BIALOSKORSKI NETO, S. Práticas de governança corporativa indicadas para monitoramento: Uma análise do nível de adoção em cooperativas agropecuárias.

REGE, São Paulo - SP, Brasil, v. 21, n. 1, p. 43-63, jan./mar. 2014

TOMAZ, D. A.; SERAFIN JUNIOR, V.; BESEN, F. G.; ALMEIDA, R. S. Estudo de Publicações sobre a Avaliação de Desempenho e Eficiência das Cooperativas de Crédito e Bancos Públicos e Privados: Características Bibliométricas. Anais do Congresso brasileiro em Gestão de Negócios, 5. Unioeste, Cascavel, PR, Brasil, 2018

UNITED NATIONS. About the International Year of Cooperatives. United Nations. 2012. Disponível em: https://social.un.org/coopsyear/about-iyc.html. Acesso em: 10 jul. 2021.

VILELA, R.E.P. Governança corporativa em cooperativas de saúde: proposição de um modelo diagnóstico. Dissertação (Mestrado). Programa de Pós-Graduação em Controladoria. Fortaleza: Universidade Federal do Ceará, 2008. 304p. 
WAKULICZ, G.; OLIVEIRA FILHO, J. T. Legislação cooperativista. Santa Maria: Universidade Federal de Santa Maria, Colégio Politécnico; Rede e-Tec Brasil, 2015. 83 p. ISBN 978-85-63573-83-4

WEITZNER, D.; PERIDIS, T. Corporate governance as part of the strategic process: rethinking the role of the board. Journal of Business Ethics, v. 102, p. 33-42, 2011.

ZYLBERSZTAJN, D. Organização de cooperativas: desafios e tendências. Revista de Administração, 29 (3), 23-32. (1994).

ZYLBERSZTAJN, D. Quatro estratégias fundamentais para cooperativas agrícolas. In: BRAGA, M.J.; REIS, B.S. (Org.) Agronegócio cooperativo: reestruturação e estratégias. Viçosa: Suprema, 2002. 